\title{
Effect of altitude on reproductive ingredient and sex allocation of different colors of Anemone obtusiloba in populations
}

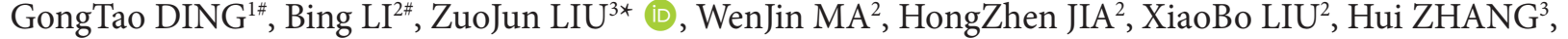 \\ ZhiGang $\mathrm{ZHAO}^{4}$, XiaoXue ZHANG ${ }^{2}$, XiaoYan ZHANG ${ }^{2}$
}

\begin{abstract}
In this study, we aimed to explore the effect of altitude on reproductive ingredient and sex allocation of different colors of Anemone obtusiloba in populations. The variations of reproductive ingredient and sex allocation of three colors of Anemone obtusiloba in different four altitudinal gradients at the eastern Qinghai Tibetan Plateau were examined. Our results showed that with the increased altitude, gynoecium/flower, androceium/flower and gynoecium/individual were increased, but androceium/individual, gynoecium number/flower, androceium number/flower, gynoecium number/ individual and androceium number/individual in three flower color of Anemone obtusiloba were decreased. Besides, male allocation and $\hat{\delta} / q$ were also decreased, which showed female-biased sex allocation. Furthermore, in the four altitudinal gradients, the individual size of same color was positively correlated with reproductive ingredient, and altitude had a direct impact on size-dependent reproductive ingredient. However, there were not certain correlations between male allocation, $\hat{\delta} / q$ and individual size in the same color of Anemone obtusiloba. Moreover, in the four altitudinal gradients, the reproductive investment of same color was positively correlated with gynoecium and androceium, but there were not certain correlations between male allocation, $\widehat{\delta} / \stackrel{+}{\mathrm{c}}$ and reproductive investment. In conclusion, altitude had a significant effect on reproductive ingredient and sex allocation in different colors of Anemone obtusiloba. Different colors of Anemone obtusiloba all increased of female function with the increased altitude. However, there were difference in influence mechanism of altitude on size-dependent reproductive ingredient and distribution between female and male function of resource.
\end{abstract}

Keywords: flower color; altitude; individual size; reproductive ingredient; sex allocation.

Practical Application: Practical Application statement: In real life, we can adjust the reproductive ingredient and sex allocation in different colors of Anemone obtusiloba through different altitudes.

\section{Introduction}

The basic activity of plant growth is to obtain, utilize and allocate resources from the environment (Gangappa \& Botto, 2016). The study of plant resource allocation mainly focuses on two aspects of reproductive allocation and sexual allocation. Reproductive allocation refers to the proportion of resources allocated to propagules to vegetative bodies, while sexual allocation mainly studies the optimal allocation of reproductive resources between male and female (Li et al., 2019). They have become a research hotspot of evolutionary biologists (Teitel et al., 2016; Coelho et al., 2005; Tonnabel et al., 2017). The change of altitude gradient provides an ideal condition for studying the ecological adaptability of plant growth and reproduction (Dostálek et al., 2018). With the increase of altitude, many environmental variables that regulate plant performance, such as temperature, growth season length and resource availability, will decrease accordingly, which will affect plant reproductive strategies, reproductive success and the relationship between plants and insects (Xu et al., 2017; Miller-Struttmann \& Galen, 2014; Ma et al., 2015). It is

predicted that if the pollination success of insect pollinators in higher altitude is limited by the lower activity of pollinators, the sex distribution pattern of plants will change (Sena et al., 2014; Dai et al., 2020; Lei et al., 2017). For self-compatible plants, it will increase investment in female function; for self-incompatible, it will increase investment in male function or flower display to attract more insects to visit flowers and improve their suitability (Zhao et al., 2005). Many entomophilous plants have different flower color characters, which can attract and guide pollinators (Vaidya et al., 2018; Reverté et al., 2016). The responses and preferences of pollinators to flower color are closely related to the development and prosperity of plants (Kemp et al., 2019). If pollinators show a negative frequency dependent selection of light color (Reverté et al., 2016; Thairu \& Brunet, 2015), the sex allocation strategies of plants are bound to change, and there may be differences in reproductive ingredient and sex allocation among different color populations. 
According to the theory of sex allocation, there is a close relationship between sex resource allocation and individual size, that is, there is a size dependent strategy (SDS) (Thomson, 2006). SDS theory have suggested that large individuals have better resource advantages, and can produce more ovules and seeds to improve female fitness, and have predicted that large individuals tend to be allocated to females, while small individuals tend to be allocated to males (Klinkhamer et al., 1997; Wright \& Barrett, 1999; Cao \& Kudo, 2008). However, other studies have proved that there is no correlation between sexual allocation and individual size (Fan et al., 2008; Méndez \& Traveset, 2003; Chen \& Gao, 2011).

The theory of sex allocation assumes that the total reproductive resources are constant and there is trade-off between male and female functions (Coelho et al., 2005). If the allocation of male functions increases, the allocation of female functions will decrease (Gangappa \& Botto, 2016; Campbell, 2000). However, it has been reported that there was no correlation between male and female function (Chen \& Gao, 2011; Campbell, 2000). Therefore, whether there is trade-off between male function and female function under the altitude gradient. If there is, whether there is regular change; if not, what is the impact mechanism?

Anemone obtusiloba is mainly distributed in the South and east of Tibet and the west of Sichuan in China. It is also distributed in Nepal, Sikkim, Bhutan and northern India (Chinese Academy of Sciences, 1980). It is a common medicinal plant in alpine meadows, and its flower color varies greatly from white to yellow. At present, several studies on Anemone obtusiloba at home and abroad are mainly focused on the comparison of reproductive and sex distribution among species in different environments. There is no report on whether there are the same sex distribution strategies among different flower color and populations in same species, and how to respond to the change of altitude. In the present study, we aimed to explore the effects of altitude on reproductive ingredient and sex allocation of different colors of Anemone obtusiloba in populations.

\section{Methods}

\subsection{General situation of study region}

The study region is located in Gannan Tibetan Autonomous Prefecture, Gansu Province, which is in the eastern part of the Qinghai Tibet Plateau $\left(101^{\circ}-103^{\circ}\right.$ E, $\left.34^{\circ}-35^{\circ} 70^{\prime} \mathrm{N}\right)$, with an altitude of $2900-4000 \mathrm{M}$. The annual average precipitation is $450-780 \mathrm{~mm}$, and the rainfall is mainly distributed from July to September. The annual average temperature is $1.8^{\circ} \mathrm{C}$, the average temperature in January is $-10.7^{\circ} \mathrm{C}$, the average temperature in July is $11.7^{\circ} \mathrm{C}$, and the maximum temperature in growth season is $23.6-28.9^{\circ} \mathrm{C}$. The annual average frost period is not less than 270 days. The grassland type is mainly alpine meadow, which is open, windy and cold (Chen et al., 2007; Chen et al., 2009).

\subsection{Subject}

Our research subject is Anemone obtusiloba, a common Ranunculaceae plant in the alpine meadow area of the eastern Qinghai Tibet Plateau. It belongs to Anemone L. of buttercup subfamily of buttercup family, and it is insect borne hermaphrodite perennial plant. Its petals are white, light yellow or yellow (Figure 1). Carpels and androceium are numerous, with one ovule in one carpel. The flowering period is from June to July, with about one week, and the fruiting period is from July to August, with more than two weeks.

\subsection{Sampling}

In June 2018, four sample areas were selected along the altitude gradient in Gannan, China (Table 1). In each sample area, 40-50 plants of white, light yellow and yellow Anemone obtusiloba were randomly collected. The aboveground part was taken in natural environment.

\subsection{Measurement}

For the collected samples, the total number of flowers per plant in flowering period was counted and expressed as $n$. The number of gynoecium and androceium of each flower of the same plant were measured, and the average values were taken to represent the number of gynoecium/flower $\left(\bar{N}_{1}\right)$ and the number of androceium/flower $\left(\bar{N}_{2}\right)$ of the plant respectively. The values of gynoecium number/individual and androceium number/individual were represented as $\left(\bar{N}_{1} \times \mathrm{n}\right)$ and $\left(\bar{N}_{2} \times \mathrm{n}\right)$, respectively. Each part of the plant was bagged and taken back to the laboratory for following experiment. All the samples were roasted at $80^{\circ} \mathrm{C}$ for $24 \mathrm{~h}$, and then the dry weight of stems and leaves of the same plant, as well as the flower weight, gynoecium and androceium of each flower were weighed by electronic balance $\left(10^{-4} \mathrm{~g}\right)$, respectively. The average values were taken to
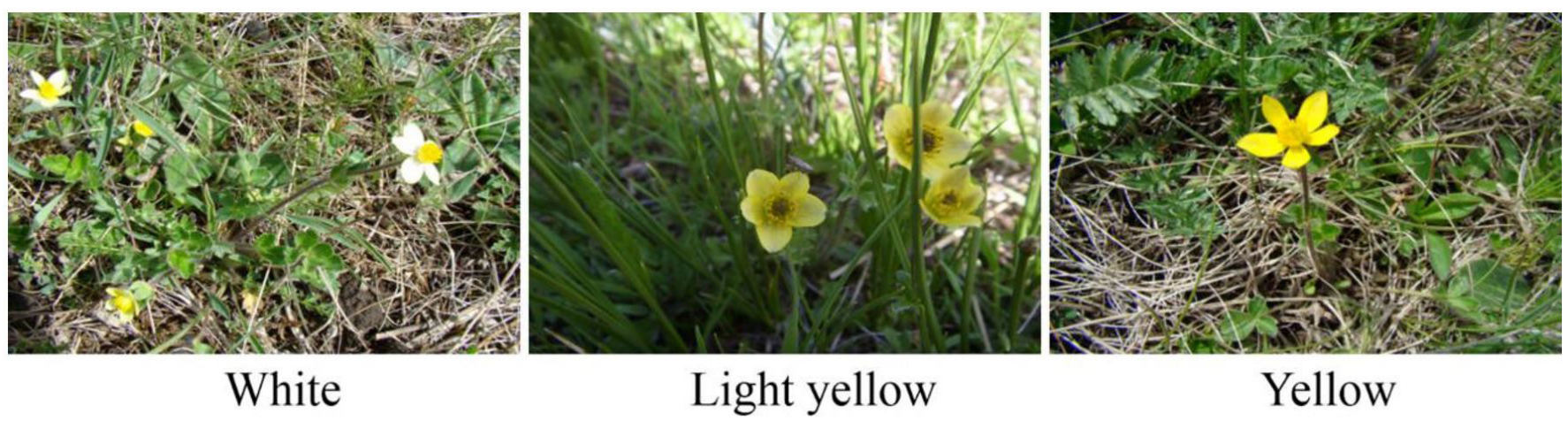

Figure 1. Different colors of Anemone obtusiloba. 
Table 1. The background of field populations studied of Anemone obtusiloba.

\begin{tabular}{|c|c|c|c|c|}
\hline Locality & Altitude/m & Longitude $^{\circ}$ & Latitude $/^{\circ}$ & Habitat \\
\hline Hezuo & 2973 & 102.53 & 34.57 & Hillside meadow \\
\hline Luqu & 3229 & 102.26 & 34.33 & Roadside bushwood \\
\hline Maqu (Azi) & 3544 & 101.51 & 33.40 & Hillside meadow \\
\hline Maqu (Awancang) & 3697 & 101.53 & 33.51 & Hillside meadow \\
\hline
\end{tabular}

Altitude, latitude, longitude measured by GPS.

represent the flower weight/flower $\left(\bar{M}_{1}\right)$, gynoecium/flower $\left(\bar{M}_{2}\right)$ and androceium/flower $\left(\bar{M}_{3}\right)$, and the flower weight/individual, gynoecium/individual and androceium/ individual were $\left(\bar{M}_{1} \times \mathrm{n}\right)$, $\left(\bar{M}_{2} \times \mathrm{n}\right)$ and $\left(\bar{M}_{3} \times \mathrm{n}\right)$, respectively.

\subsection{Statistical analysis}

Statistical analysis was made by software SPSS22.0 (International Business Machines, corp., Armonk, NY, USA). The individual size is represented by the dry weight of aboveground vegetative body (stem and leaf). The female allocation was expressed as the percentage of gynoecium/individual to flower weight/individual, while the male allocation was expressed as the percentage of androceium/individual to flower weight/ individual. $\delta / 0$ was expressed as (androceium/individual)/(gynoecium/individual). Bivariate correlations and linear regression were used to analyze the correlation and linear regression of reproductive ingredient, sex allocation and altitude. In the analysis of reproductive ingredient and sex allocation among different altitudes, the correlation between individual size $(X)$ and reproductive ingredient $(Y)$ was analyzed with algometric model $Y=\mathrm{a} X^{\mathrm{b}}$ according to the algometric relationship between individual size and reproductive ingredient (Klinkhamer et al., 1997; Wright \& Barrett, 1999). The linear equation is obtained by logarithmic transformation of $Y=\mathrm{a} X^{\mathrm{b}}: \log _{10} Y=\log _{10} \mathrm{a}+\operatorname{blog}_{10} X$. Univariate in the general linear model menu was used to compare the differences of slope $\mathrm{b}$ and intercept $\log _{10}$ a between populations at different altitudes (Zhigang et al., 2006). In the analysis of whether there is tradeoff between male and female resource allocation, the rate model $y / x=a x^{B-1}$ of female and male allocation and reproductive biomass is obtained through the rate model transformation. $y / x$ is the female or male allocation, then the change of $y / x$ with $x$ depends on the value of regression coefficient $b-1$. If the $b-1$ values of both sexes are $<0$ or $>1$, there is no trade-off between the two sexes. Differences were considered statistically significant when $P<0.05$.

\section{Results}

\subsection{Relationship between altitude and reproductive ingredient and sex allocation}

As shown in Figure 2, with the increase of altitude, the gynoecium/flower of different colors of Anemone obtusiloba were significantly increased $(P<0.01)$. The androceium/flower were also increased with the increase of altitude, and those of white Anemone obtusiloba reached a more significant level $(P<0.05)$. The gynoecium/individual of the three colors were increased with the increase of altitude, and the light yellow showed a significant level $(P<0.05)$, while the androceium/individual were decreased, and the yellow showed a very significant level $(P<0.01)$. The gynoecium number/flowers, androceium number/flowers, gynoecium number/individual and androceium number/individual of the three flower colors were all decreased with the increase of altitude, and gynoecium/flower in white and yellow, androceium/flower in light yellow and yellow, gynoecium/individual in yellow and androceium/individual in light yellow and yellow reached extremely significant level $(P<0.01)$.

As shown in Figure 3, the male allocation of different colors was decreased with the increase of altitude, even light yellow and yellow showed a significant level $(P<0.01)$. Except that the female allocation of the light yellow increased significantly with the increase of altitude $(P<0.05)$, those of the white and yellow were decreased. In addition, $\delta / q$ of the three colors was decreased with the increase of altitude, especially light yellow and yellow showed a significant level $(P<0.01)$. Taken together, the results showed that with the increase of altitude, the sex allocation of different colors had different responses, and all of them showed a partial female allocation.

\subsection{The relationship between individual size and reproductive ingredient and sex allocation}

It showed that at different altitudes, the reproductive ingredient of the three colors was increased with the increase of individual size (Table 2). The gynoecium/flower of the light yellow was significantly increased with the increase of individual size $(P<0.05)$, and the size dependent intercept had a very significant difference $(P<0.01)$, indicating that the altitude had a direct impact on the gynoecium / flower. There was a significant positive correlation between androceium/flower and individual size of the white and light yellow $(P<0.05)$, and the intercept was significantly different between the altitudes $(P<0.01)$, indicating that altitude had a direct impact on the androceium /flower of the white and light yellow.

The gynoecium/individual of the three colors was increased significantly with the increase of individual size $(P<0.01)$, and the intercept of size dependence had a significant difference $(P<0.01)$, indicating that altitude had a direct impact on individual size dependent pistil input. The androceium/individual of the three flower colors also increased significantly with the increase of individual size $(P<0.01)$, and the intercept was different at the altitude, among which the difference in the white was very significant $(P<0.01)$, and in the light yellow and yellow were significant $(P<0.05)$, indicating that altitude had a direct impact on the stamen input of the three flower colors. 

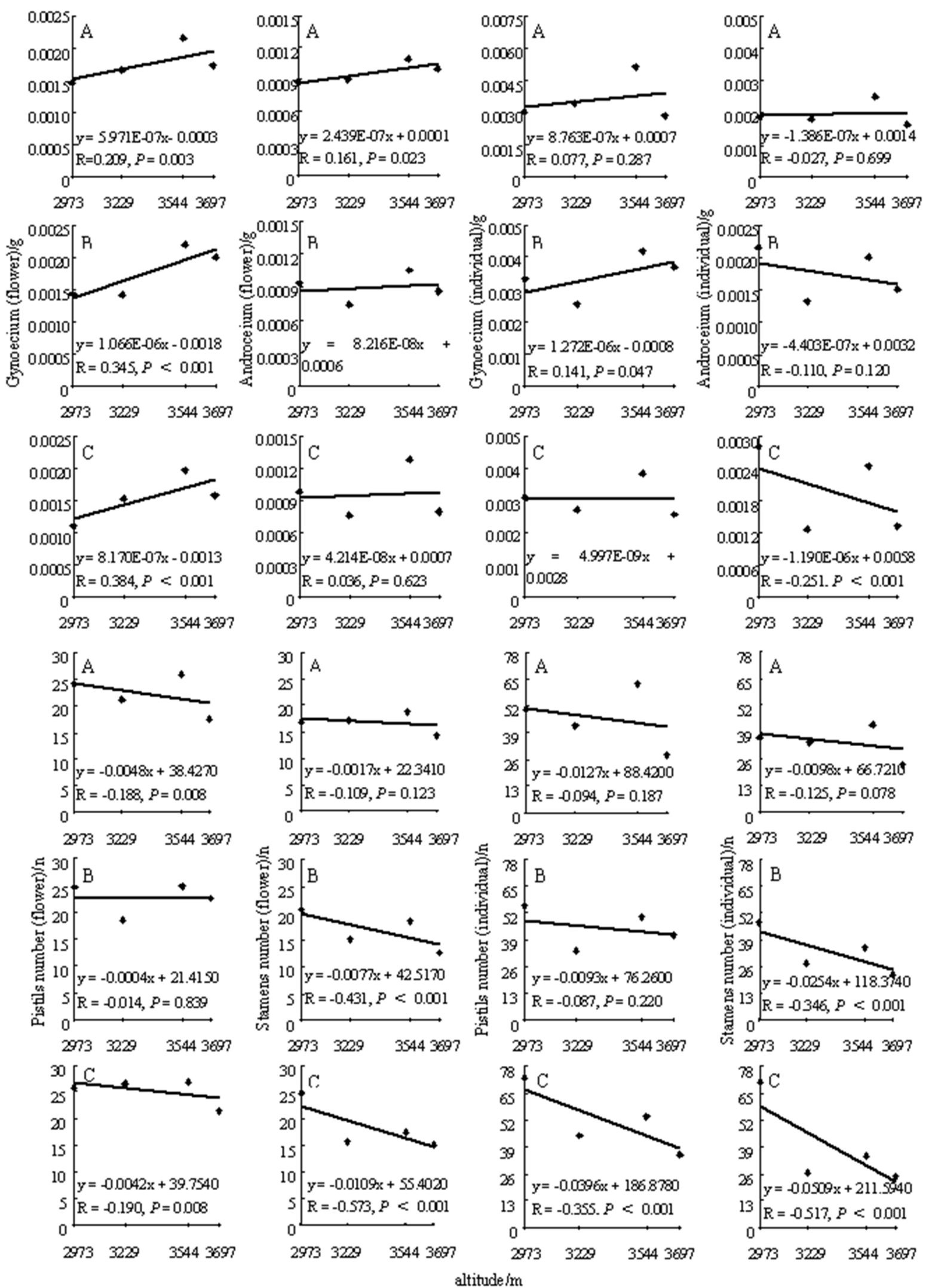

Figure 2. Relationships between reproductive ingredient of different colors Anemone obtusiloba and altitude. Bivariate correlations and linear regression were used to analyze the correlation and linear regression of reproductive ingredient, sex allocation and altitude. The linear regression equation was expressed as $y=a x+b$, (R) was represented as regression coefficient; (P) was represented as statistical difference; (A) White; (B) Light yellow; (C) Yellow. 

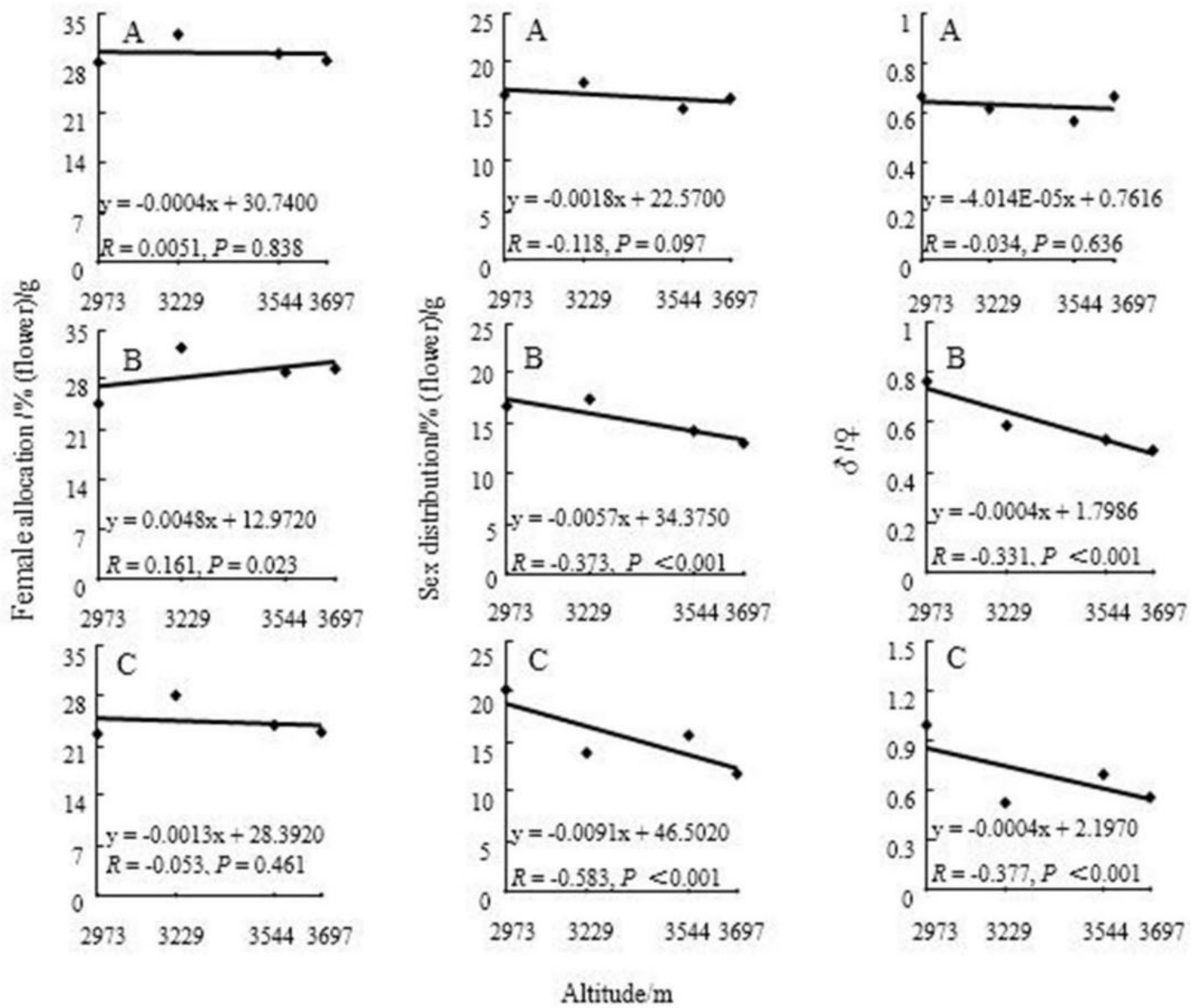

Figure 3. Relationships between sex allocation of different colors of Anemone obtusiloba and altitude. Bivariate correlations and linear regression were used to analyze the correlation and linear regression of reproductive ingredient, sex allocation and altitude. The linear regression equation was expressed as $y=a x+b$, (R) was represented as regression coefficient; (P) was represented as statistical difference; (A) White; (B) Light yellow; (C) Yellow.

The gynoecium number/flower of the light yellow increased significantly with the increase of individual size $(P<0.05)$, and the intercept of size dependence was significantly different between the altitudes $(P<0.05)$, indicating that altitude had a direct impact on gynoecium number/flower.

The gynoecium number/individual and androceium number/individual increased significantly with the increase of individual size $(P<0.01)$, which indicated that altitude had a direct impact on gynoecium number/individual and androceium number/ individual in the three flower colors.

Moreover, female allocation, male allocation and $\hat{\delta} / 9$ had no significant regular change with individual size, which showed that these characteristics did not exist size dependence phenomenon, and cannot explain the SDS model (Table 3).

\subsection{Trade off of reproductive resources to female and male}

As shown in Table 4, at different altitudes, the biomass of female and male of the three flower color were significantly increased with the increase of reproductive input $(P<0.01)$. There were no regular changes in female allocation, male allocation and $\delta / P(P>0.05)$. The results showed that no matter the biomass or allocation ratio of female and male, there was no trade-off phenomenon between them.

\section{Discussion}

With the increase of altitude, the gynoecium/flower, androceium/flower and gynoecium/individual of the three different flowers were increased, while the androceium/individual was decreased, indicating that the input of female organs increased in different flower colors of Anemone obtusiloba at individual or single flower levels. This is consistent with Zhao et al. conclusion that if the plant in high altitude area is limited by pollination, self-compatible species will increase the input to female function (Zhao et al., 2005). However, this is different from fan Bao et al. that the gynoecium of Anemone obtusiloba in the high altitude area is significantly reduced (Fan et al., 2008). The pistil number/flower, stamen number/flower, pistil number/individual and stamen number/ flower of the three flower colors were all decreased with the increase of altitude, which may be due to the 


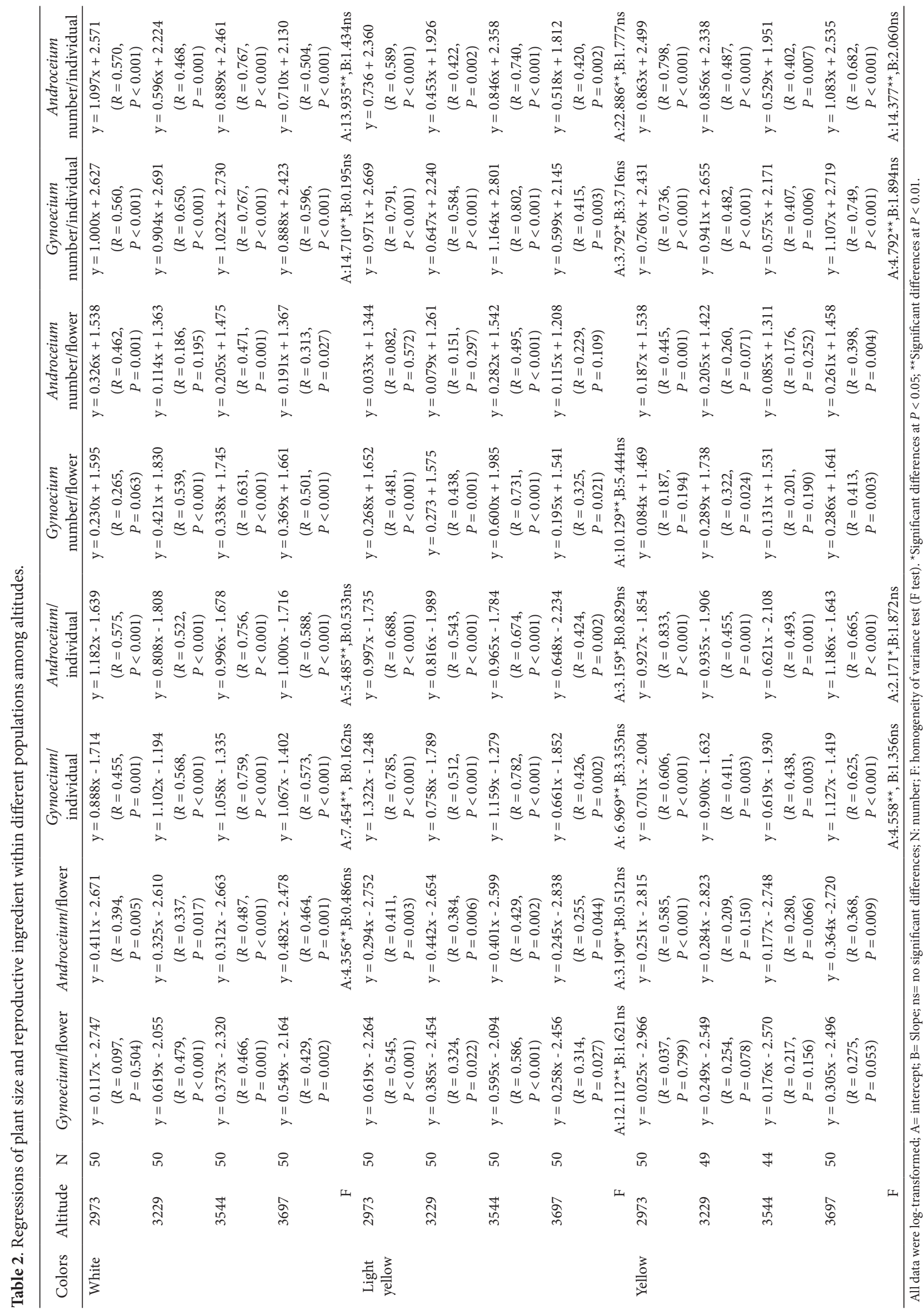


Original Article

Ding et al.

Table 3. Regressions of plant size and sex allocation within different populations among altitudes.

\begin{tabular}{|c|c|c|c|c|c|}
\hline Colors & Altitude $(\mathrm{m})$ & $\mathrm{N}$ & Stamen allocation (\%) & Sex distribution (\%) & $\hat{0} / 9$ \\
\hline \multirow[t]{9}{*}{ White } & \multirow[t]{2}{*}{2973} & \multirow[t]{2}{*}{50} & $y=-0.271 x+1.163$ & $y=0.023 x+1.238$ & $y=0.297 x+0.075$ \\
\hline & & & $(R=-0.310, P=0.028)$ & $(R=0.034, P=0.817)$ & $(\mathrm{R}=0.219, P=0.126)$ \\
\hline & \multirow[t]{2}{*}{3229} & \multirow[t]{2}{*}{50} & $y=0.236 x+1.782$ & $y=-0.580 x+1.168$ & $y=-0.295 x-0.615$ \\
\hline & & & $(R=0.319, P=0.024)$ & $(R=-0.085, P=0.537)$ & $(R=-0.285, P=0.045)$ \\
\hline & \multirow[t]{2}{*}{3544} & \multirow[t]{2}{*}{50} & $y=0.011 x+1.468$ & $y=-0.051 x+1.125$ & $y=-0.062 x-0.343$ \\
\hline & & & $(R=0.025, P=0.865)$ & $(R=-0.141, P=0.330)$ & $(R=-0.089, P=0.537)$ \\
\hline & \multirow[t]{2}{*}{3697} & \multirow[t]{2}{*}{50} & $y=0.078 x+1.526$ & $y=0.011+1.212$ & $y=-0.067 x-0.314$ \\
\hline & & & $(R=0.095, P=0.513)$ & $(R=0.017, P=0.909)$ & $(R=-0.052, P=0.718)$ \\
\hline & \multicolumn{2}{|c|}{$\mathrm{F}$} & & & \\
\hline \multirow{9}{*}{$\begin{array}{l}\text { Light } \\
\text { yellow }\end{array}$} & \multirow[t]{2}{*}{2973} & \multirow[t]{2}{*}{50} & $y=0.221 x+1.594$ & $y=-0.104 x+1.107$ & $y=-0.325 x-0.487$ \\
\hline & & & $(R=0.303, P=0.032)$ & $(R=-0.225, P=0.116)$ & $(R=-0.325, P=0.021)$ \\
\hline & \multirow[t]{2}{*}{3229} & \multirow[t]{2}{*}{50} & $y=0.003 x-1.500$ & $y=0.061 x+1.300$ & $y=0.058 x-0.200$ \\
\hline & & & $(R=0.005, P=0.975)$ & $(R=0.093, P=0.520)$ & $(R=0.064, P=0.656)$ \\
\hline & \multirow[t]{2}{*}{3544} & \multirow[t]{2}{*}{50} & $y=0.163 x+1.619$ & $y=-0.031 x+1.113$ & $y=-0.194 x-0.505$ \\
\hline & & & $(R=0.306, P=0.031)$ & $(R=-0.069, P=0.634)$ & $(R=-0.235, P=0.100)$ \\
\hline & \multirow[t]{2}{*}{3697} & \multirow[t]{2}{*}{50} & $y=0.038 x+1.497$ & $y=0.024 x+1.115$ & $y=-0.013 x-0.382$ \\
\hline & & & $(R=0.064, P=0.659)$ & $(R=0.031, P=0.828)$ & $(R=-0.012, P=0.936)$ \\
\hline & 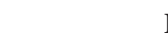 & & & & \\
\hline \multirow[t]{8}{*}{ Yellow } & \multirow[t]{2}{*}{2973} & 50 & $y=-0.176 x+1.192$ & $y=0.049 x+1.343$ & $y=0.226 x+0.150$ \\
\hline & & & $(R=-0.318, P=0.024)$ & $(R=0.171, P=0.234)$ & $(R=0.303, P=0.032)$ \\
\hline & \multirow[t]{2}{*}{3229} & \multirow[t]{2}{*}{49} & $y=-0.066 x+1.363$ & $y=-0.031 x+1.089$ & $y=0.035 x-0.274$ \\
\hline & & & $(R=-0.086, P=0.558)$ & $(R=-0.030, P=0.840)$ & $(R=0.027, P=0.855)$ \\
\hline & \multirow[t]{2}{*}{3544} & \multirow[t]{2}{*}{44} & $y=-0.089 x+1.288$ & $y=-0.087 x+1.109$ & $y=0.002 x-0.178$ \\
\hline & & & $(R=-0.163, P=0.290)$ & $(R=-0.217, P=0.157)$ & $(R=0.002, P=0.988)$ \\
\hline & \multirow[t]{2}{*}{3697} & \multirow[t]{2}{*}{50} & $y=-0.076 x+1.257$ & $y=-0.017 x+1.033$ & $y=0.059 x-0.224$ \\
\hline & & & $(R=-0.107, P=0.461)$ & $(R=-0.022, P=0.882)$ & $(R=0.053, P=0.714)$ \\
\hline
\end{tabular}

$\mathrm{N}$ : number; $\precsim /$ : : stamen/pistil.

Table 4. Regression analyses between reproductive resource status (x) and two sex allocation (y) within population (both $\mathrm{x}$ and $\mathrm{y}$ are In-transformed).

\begin{tabular}{|c|c|c|c|c|c|c|c|c|c|c|c|c|c|}
\hline \multirow[t]{2}{*}{ Colors } & \multirow{2}{*}{$\begin{array}{l}\text { Reproductive } \\
\text { component }\end{array}$} & \multicolumn{3}{|c|}{$2973 \mathrm{~m}$} & \multicolumn{3}{|c|}{$3229 \mathrm{~m}$} & \multicolumn{3}{|c|}{$3544 \mathrm{~m}$} & \multicolumn{3}{|c|}{$3697 \mathrm{~m}$} \\
\hline & & $\mathrm{N}$ & $R$ & b-1 & $\mathrm{N}$ & $R$ & b-1 & $\mathrm{N}$ & $R$ & b-1 & $\mathrm{N}$ & $R$ & b-1 \\
\hline \multirow[t]{5}{*}{ White } & Male & 50 & $0.952^{\star *}$ & 0.895 & 50 & $0.950^{* *}$ & 1.304 & 50 & $0.949^{\star *}$ & 1.036 & 50 & $0.905^{* *}$ & 1.156 \\
\hline & Female & 50 & $0.942 * *$ & 1.057 & 50 & $0.898^{* *}$ & 0.983 & 50 & 0.962 ** & 0.992 & 50 & $0.919^{* *}$ & 1.073 \\
\hline & Male allocation & 50 & $-0.100 \mathrm{~ns}$ & -0.048 & 50 & $0.580^{* *}$ & 0.304 & 50 & $0.103 \mathrm{~ns}$ & 0.036 & 50 & $0.277 \mathrm{~ns}$ & 0.156 \\
\hline & Female allocation & 50 & $0.149 \mathrm{~ns}$ & 0.570 & 50 & $0.035 \mathrm{~ns}$ & 0.017 & 50 & $-0.029 \mathrm{~ns}$ & -0.008 & 50 & $-0.156 \mathrm{~ns}$ & -0.073 \\
\hline & $3 / q$ & 50 & $0.143 \mathrm{~ns}$ & 0.105 & 50 & $-0.438^{*}$ & -0.321 & 50 & $-0.081 \mathrm{~ns}$ & -0.044 & 50 & $-0.096 \mathrm{~ns}$ & -0.084 \\
\hline \multirow{5}{*}{$\begin{array}{l}\text { Light } \\
\text { yellow }\end{array}$} & Male & 50 & $0.904^{* *}$ & 1.086 & 50 & $0.883^{* *}$ & 1.048 & 50 & $0.936^{* *}$ & 1.075 & 50 & 0.931 ** & 1.121 \\
\hline & Female & 50 & $0.948^{\star *}$ & 0.979 & 50 & $0.904^{* *}$ & 1.088 & 50 & $0.951^{\star *}$ & 1.055 & 50 & $0.863^{* *}$ & 1.022 \\
\hline & Male allocation & 50 & $0.165 \mathrm{~ns}$ & 0.086 & 50 & $0.086 \mathrm{~ns}$ & 0.048 & 50 & $0.181 \mathrm{~ns}$ & 0.075 & 50 & $0.267 \mathrm{~ns}$ & 0.121 \\
\hline & Female allocation & 50 & $-0.063 \mathrm{~ns}$ & -0.021 & 50 & $0.169 \mathrm{~ns}$ & 0.088 & 50 & $0.159 \mathrm{~ns}$ & 0.055 & 50 & $0.037 \mathrm{~ns}$ & 0.022 \\
\hline & $3 / q$ & 50 & $-0.150 \mathrm{~ns}$ & -0.107 & 50 & $0.056 \mathrm{~ns}$ & 0.040 & 50 & $-0.031 \mathrm{~ns}$ & -0.020 & 50 & $-0.113 \mathrm{~ns}$ & -0.099 \\
\hline \multirow[t]{5}{*}{ Yellow } & Male & 50 & $0.878^{* *}$ & 0.960 & 49 & $0.948^{* *}$ & 1.178 & 44 & $0.924^{* *}$ & 1.028 & 50 & $0.920^{* *}$ & 1.064 \\
\hline & Female & 50 & $0.966^{\star *}$ & 1.016 & 49 & 0.864 ** & 1.006 & 44 & $0.950^{\star *}$ & 0.942 & 50 & $0.894^{* *}$ & 1.023 \\
\hline & Male allocation & 50 & $-0.077 \mathrm{~ns}$ & -0.040 & 49 & 0.409 * & 0.178 & 44 & $0.066 \mathrm{~ns}$ & 0.028 & 50 & $0.140 \mathrm{~ns}$ & 0.064 \\
\hline & Female allocation & 50 & $0.016 \mathrm{~ns}$ & 0.016 & 49 & $0.010 \mathrm{~ns}$ & 0.006 & 44 & $-0.184 \mathrm{~ns}$ & -0.058 & 50 & $0.045 \mathrm{~ns}$ & 0.023 \\
\hline & $3 / 9$ & 50 & $0.079 \mathrm{~ns}$ & 0.056 & 49 & $-0.232 \mathrm{~ns}$ & -0.172 & 44 & $-0.148 \mathrm{~ns}$ & -0.086 & 50 & $-0.058 \mathrm{~ns}$ & -0.042 \\
\hline
\end{tabular}

$\mathrm{ns}=$ no significant differences; $\mathrm{N}$ : number; ${ }^{\Uparrow} / P$ : stamen/pistil; R: correlation coefficient (R value). ${ }^{*}$ Significant differences at $P<0.05 ;{ }^{*}$ Significant differences at $P<0.01$.

corresponding decrease of temperature, growth season length, resource availability, insect richness, diversity and activity with the increase of altitude, as well as the stamen input and number of plants (Xu et al., 2017; Miller-Struttmann \& Galen, 2014).
Therefore, only by increasing the input of gynoecium, can we ensure the success rate of survival and reproduction. The above results show that the reproductive ingredient of different flower colors of Anemone obtusiloba make adaptive adjustment to the 
harsh environment at high altitude, that is, with the increase of altitude, the male input is reduced while the female input is increased, and this increase may pay more attention to the quality of ovules rather than the quantity. Moreover, the sex allocation of the three colors was decreased with the increase of altitude, showing a partial female allocation.

For the differences between the above results and the variation of reproductive ingredient and sex allocation of Anemone obtusiloba with altitude, there may be the following reasons. First, soil moisture is different (Marcos \& Traveset, 2003). Because the vegetation coverage of the sample plots may be different, the soil surface humidity may be different, resulting in different relative resources and reproductive ingredient of reproductive organs, thus causing changes in reproductive ingredient and sex allocation (Huang et al., 2011). Second, soil nutrients are different. Soil factors are closely related to the variation of plant phenotypic characters (Zhang et al., 2011). There may be higher soil nutrients in high altitude areas, and there are enough mineral resources allocated to the reproductive part, which has an impact on reproductive ingredient and sex allocation of three flower colors of Anemone obtusiloba (Zhigang et al., 2006; Fabbro \& Körner, 2004). Third, the pollination environment may be different. With the increase of altitude, in spite of the unfavorable pollination environment and the limited total available resources, the genetic variability and evolutionary adaptation potential of the population in the harsh environment can be guaranteed only by ensuring the resource input of sexual reproduction (Fabbro \& Körner, 2004; Fan et al., 2008; Fan \& Yang, 2009a). Forth, because of the plasticity of plants, it may be affected by their own heredity. These plasticity responses affect the fitness of plants, thus affecting the survival and reproduction. Fifth, in perennial herbs, the amount of resources stored in the underground part also have a complex impact on the resource allocation between the aboveground parts of plants. Therefore, different habitats and genetic characteristics are closely related to reproductive strategies. Therefore, we need to analyze the mating system, population density, soil moisture and nutrients of different altitude populations, and to combine with the interactive transplanting, pollinator access frequency, and artificial control experiments, so as to obtain more comprehensively explanation on the relationship between the sex allocation and genetic factors and the environment.

Our research showed that the individual size of the three flower colors was positively correlated with gynoecium/flower, androceium/flower, gynoecium/individual, androceium/individual, pistil number/flower, stamen number/flower, pistil number/ individual, stamen number/ individual under different altitude gradients. This is consistent with the conclusion of a large number of studies (Gangappa \& Botto, 2016), but there are also some different views (Fan et al., 2008; Chen \& Gao, 2011). Altitude has a direct impact on size dependent reproductive ingredient of the three flower colors, which indicates that different flower colors will adjust its resource allocation to reproductive structure according to the change of the external environment, so as to maximize its reproductive effectiveness.

According to size dependent strategy (SDS), in entomophilous plant, the large individual is the sex allocation of partial female, while the small individual is the sex allocation of partial male
(Gangappa \& Botto, 2016; Thomson, 2006; Cao \& Kudo, 2008; Marcos \& Traveset, 2003). However, some studies have not found a correlation between individual size and sex allocation (Teitel et al., 2016; Méndez \& Traveset, 2003; Chen \& Gao, 2011). It shows that the relationship between individual size and sexual expression of these plants is weak, and SDS may not be universal. Even plants of the same family may have different sexual distribution patterns due to species and habitat quality. Our results showed that thise three flower colors do not conform to SDS phenomenon, but more conform to Sato model (Fan \& Yang, 2009b). The difference of resource pool used by plants will affect the sex allocation of individual size dependence. However, for self-compatible species, the optimal allocation of male function does not depend on individual size. Therefore, more follow-up studies are needed to find out whether the sex allocation strategies of different flower colors of Anemone obtusiloba are related to their phylogenetic level and have certain regularity.

The theory of sexual allocation assumes that the total reproductive resources are constant, and there is a trade-off between male and female functions. If the allocation or input of male functions increases, the allocation or input of male and female functions will decrease (Coelho et al., 2005). The trade-off relationship between male and female functions has been confirmed (Gangappa \& Botto, 2016), but the results of this study do not show the trade-off between male and female functions. The trade-off between the sexes at the individual level has also been difficult to confirm in previous studies (Sato, 2004; Mazer \& Dawson, 2001). This may be due to the fact that plants have to allocate resources among many different life history traits.

\section{Conclusion}

The altitude has an important influence on the reproductive ingredient and sex allocation of different colors of Anemone obtusiloba, and the female function has been adjusted with the elevation. However, the influence of altitude on reproductive ingredient, the mechanism and resource allocation between male and female function are different among flower colors, which shows that they are affected by flower color characteristics and environmental conditions.

\section{Ethical approval}

This study is approved by Ethics Committee of Northwest Minzu University.

\section{Conflict of interest}

None.

\section{Availability of data and material}

The datasets used or analysed during the current study are available from the corresponding author on reasonable request.

\section{Funding}

This study was supported by Gansu Provincial Science and Technology Grant (17YF1WA166); Funded by the National Natural Science Foundation of China (30960066). 


\section{Author contributions}

Guarantor of integrity of the entire study, GongTao Ding. Study concepts, ZuoJun Liu. Study design, Bing Li, ZhiGang Zhao. Experimental studies, Bing Li, WenJin Ma, HongZhen Jia, XiaoBo Liu, XiaoXue Zhang. Data analysis, XiaoBo Liu, Hui Zhang, XiaoYan Zhang. Manuscript preparation, editing and review, GongTao Ding, Bing Li.

\section{References}

Campbell, D. R. (2000). Experimental tests of sex-allocation theory in plants. Trends in Ecology \& Evolution, 15(6), 227-232. http://dx.doi. org/10.1016/S0169-5347(00)01872-3. PMid:10802547.

Cao, G. X., \& Kudo, G. (2008). Size-dependent sex allocation in a monocarpic perennial herb, Cardiocrinum cordatum (Liliaceae). Plant Ecology, 194(1), 99-107. http://dx.doi.org/10.1007/s11258007-9277-x.

Chen, X. L., Jing, G. H., Guo, H. (2007) The characteristics and biological significance of the skin ornamentation of 19 species of Artemisia selengensis in the alpine meadow on the eastern margin of the Qinghai Tibet Plateau. Acta Pratica Sinica. 16(2), 60-68.

Chen, X. L., Liang, Y., Qi, W., \& Su, M. (2009) Study on the reproductive distribution of annual Gentiana and the trade-off relationship between flower size and quantity. Acta Pratica Sinica. 18(5), 58-66.

Chen, Z. F., \& Gao, J. Y. (2011). Study on sex distribution of Hedychium coccineum dependent on individual size. Journal of Yunnan University, 33(5), 594-603. [natural science edition]

Chinese Academy of Sciences. (1980). Flora of China (Chap. 28, p. 34). Beijing: Science Press.

Coelho, F. F., Deboni, L., \& Lopes, F. S. (2005). Density-dependent reproductive and vegetative allocation in the aquatic plant Pistia stratiotes (Araceae). Revista de Biología Tropical, 53(3-4), 369-376. http://dx.doi.org/10.15517/rbt.v53i3-4.14599. PMid:17354448.

Dai, L., Zheng, J., Wang, Y., Sun, Y., \& Chen, H. (2020). Survival physiology and sex ratio of the Chinese white pine beetle Dendroctonus armandi (Coleoptera: Scolytinae) during host colonization and overwintering. Bulletin of Entomological Research, 110(1), 115-122. http://dx.doi. org/10.1017/S0007485319000361. PMid:31138336.

Dostálek, T., Rokaya, M. B., \& Münzbergová, Z. (2018). Altitude, habitat type and herbivore damage interact in their effects on plant population dynamics. PLoS One, 13(12), e0209149. http://dx.doi. org/10.1371/journal.pone.0209149. PMid:30557339.

Fabbro, T., \& Körner, C. (2004). Altitudinal differences in flower traits and reproductive allocation. Flora, 199(1), 70-81. http://dx.doi. org/10.1078/0367-2530-00128.

Fan, B. L., Meng, J. L., \& Zhao, Z. G. (2008). Effects of altitude on reproductive characteristics and resource allocation of Ranunculaceae plants in the eastern Qinghai Tibet Plateau. Acta Botanica Sinica, 28(4), 805-811.

Fan, D. M., \& Yang, Y. P. (2009a). Altitudinal variations in flower and bulbil production of an alpine perennial, Polygonum viviparum (Polygonaceae). Plant Biology, 11(3), 493-497. http://dx.doi. org/10.1111/j.1438-8677.2008.00188.x. PMid:19470121.

Fan, D., \& Yang, Y. (2009b). Comparison of reproductive strategies of Polygonum viviparum (Polygonaceae) in different habitats. Yunnan Plant Research, 31(2), 153-157.

Gangappa, S. N., \& Botto, J. F. (2016). The multifaceted roles of HY5 in plant growth and development. Molecular Plant, 9(10), 1353-1365. http://dx.doi.org/10.1016/j.molp.2016.07.002. PMid:27435853.
Huang, D. Q., Yu, L., \& Zhang, Y. S. (2011) A comparative study on aboveground biomass and its relationship with soil moisture in natural grassland on the northern slope of Qilian Mountain. Acta Pratacultura, 20(3), 20-27.

Kemp, J. E., Bergh, N. G., Soares, M., \& Ellis, A. G. (2019). Dominant pollinators drive non-random community assembly and shared flower colour patterns in daisy communities. Annals of Botany, 123(2), 277-288. http://dx.doi.org/10.1093/aob/mcy126. PMid:29992277.

Klinkhamer, P. G. L., De Jong, T. J., \& Metz, H. (1997). Sex and size in cosexual plants. Trends in Ecology \& Evolution, 12(7), 260-265. http://dx.doi.org/10.1016/S0169-5347(97)01078-1. PMid:21238063.

Lei, Y., Jiang, Y., Chen, K., Duan, B., Zhang, S., Korpelainen, H., Niinemets, Ü., \& Li, C. (2017). Reproductive investments driven by sex and altitude in sympatric Populus and Salix trees. Tree Physiology, 37(11), 1503-1514. http://dx.doi.org/10.1093/treephys/ tpx075. PMid:28985430.

Li, C., Li, H., \& Yang, Y. (2019). Senescence in growth and reproductive allocation in a bunchgrass. Plant Biology, 21(2), 300-306. http:// dx.doi.org/10.1111/plb.12929. PMid:30362257.

Ma, L., Sun, X., Kong, X., Galvan, J. V., Li, X., Yang, S., Yang, Y., Yang, Y., \& Hu, X. (2015). Physiological, biochemical and proteomics analysis reveals the adaptation strategies of the alpine plant Potentilla saundersiana at altitude gradient of the Northwestern Tibetan Plateau. Journal of Proteomics, 112, 63-82. http://dx.doi.org/10.1016/j. jprot.2014.08.009. PMid:25181701.

Marcos, M., \& Traveset, A. (2003). Sexual allocation in single-flowered hermaphroditic individual in relation to plant and flower size. Oecologia, 137(1), 69-75. http://dx.doi.org/10.1007/s00442-0031319-z. PMid:12844252.

Mazer, S. J., \& Dawson, K. A. (2001). Size-Dependent sex allocation within flowers of the annual herb Clarkia unguiculata (Onagraceae), ontogenetic and among-plant variation. American Journal of Botany, 88(5), 819-831. http://dx.doi.org/10.2307/2657034. PMid:11353707.

Méndez, M., \& Traveset, A. (2003). Sexual allocation in single-flowered hermaphroditic individuals in relation to plant and flower size. Oecologia, 137(1), 69-75. http://dx.doi.org/10.1007/s00442-0031319-z. PMid:12844252.

Miller-Struttmann, N. E., \& Galen, C. (2014). High-altitude multitaskers: bumble bee food plant use broadens along an altitudinal productivity gradient. Oecologia, 176(4), 1033-1045. http://dx.doi. org/10.1007/s00442-014-3066-8. PMid:25199658.

Reverté, S., Retana, J., Gómez, J. M., \& Bosch, J. (2016). Pollinators show flower colour preferences but flowers with similar colours do not attract similar pollinators. Annals of Botany, 118(2), 249-257. http://dx.doi.org/10.1093/aob/mcw103. PMid:27325897.

Sato, T. (2004). Size-dependent sex allocation in hermaphroditic plants: the effects of resource pool and self-incompatibility. Journal of Theoretical Biology, 227(2), 265-275. http://dx.doi.org/10.1016/j. jtbi.2003.11.006. PMid:14990390.

Sena, L., Deressa, W., \& Ali, A. (2014). Dynamics of Plasmodium falciparium and Plasmodium vivax in a micro-ecological setting, Southwest Ethiopia: effects of altitude and proximity to a dam. BMC Infectious Diseases, 14(1), 625. http://dx.doi.org/10.1186/s12879014-0625-x. PMid:25407982.

Teitel, Z., Pickup, M., Field, D. L., \& Barrett, S. C. (2016). The dynamics of resource allocation and costs of reproduction in a sexually dimorphic, wind-pollinated dioecious plant. Plant Biology, 18(1), 98-103. http://dx.doi.org/10.1111/plb.12336. PMid:25865555.

Thairu, M. W., \& Brunet, J. (2015). The role of pollinators in maintaining variation in flower colour in the Rocky Mountain columbine, 
Aquilegia coerulea. Annals of Botany, 115(6), 971-979. http://dx.doi. org/10.1093/aob/mcv028. PMid:25808657.

Thomson, J. D. (2006). Tactics for male reproductive success in plants: contrasting insights of sex allocation theory and pollen presentation theory. Integrative and Comparative Biology, 46(4), 390-397. http:// dx.doi.org/10.1093/icb/icj046. PMid:21672751.

Tonnabel, J., David, P., \& Pannell, J. R. (2017). Sex-specific strategies of resource allocation in response to competition for light in a dioecious plant. Oecologia, 185(4), 675-686.

Vaidya, P., McDurmon, A., Mattoon, E., Keefe, M., Carley, L., Lee, C. R., Bingham, R., \& Anderson, J. T. (2018). Ecological causes and consequences of flower color polymorphism in a self-pollinating plant (Boechera stricta). The New Phytologist, 218(1), 380-392. http:// dx.doi.org/10.1111/nph.14998. PMid:29369384.
Wright, S. I., \& Barrett, S. C. H. (1999). Size-dependent gender modification in a hermaphroditic perennial herb. Proceedings of the Royal Society B, 266(1416), 225-232. http://dx.doi.org/10.1098/rspb.1999.0626.

Xu, M., Ma, L., Jia, Y., \& Liu, M. (2017). Integrating the effects of latitude and altitude on the spatial differentiation of plant community diversity in a mountainous ecosystem. PLoS One, 12(4), e0176866.

Zhang, M. Q., Wang, Y. R., \& Zhang, J. Y. (2011). Study on genetic diversity of propagation related characteristics of Elymus verticillata germplasm resources. Acta Pratica Sinica, 20(3), 182-191.

Zhao, Z. G., Du, G. Z., \& Liu, Z. J. (2005). Sexual distribution of monogamous plants. Journal of Ecology, 25(10), 2725-2733.

Zhigang, Z., Guozhen, D., Xianhui, Z., Mantang, W., \& Qingji, R. (2006). Variations with altitude in reproductive traits and resource allocation of three Tibetan species of Ranunculaceae. Australian Journal of Botany, 54(7), 691-700. http://dx.doi.org/10.1071/BT05015. 